\title{
Mídia e vínculo eleitoral: a literatura internacional e o caso brasileiro
}

\section{Luis Felipe Miguel}

Universidade de Brasília

\begin{abstract}
Resumo
O caráter democrático das instituições representativas depende da qualidade do vínculo eleitoral, isto é, da capacidade que o processo eleitoral possui de vincular a ação dos representantes à vontade dos representados. Um elemento-chave no processo é a informação - sobre o comportamento anterior dos políticos, sobre sua plataforma, sobre a agenda pública. Uma vasta literatura discutiu a influência dos principais provedores de informação das sociedades contemporâneas (a mídia de massa) na relação entre representantes e representados. Mas as particularidades do campo político brasileiro colocam em perspectiva a literatura internacional.
\end{abstract}

Palavras-chave: representação política, meios de comunicação de massa, eleições, política brasileira.

\begin{abstract}
The democratic character of representative institutions depends on the ties that elections can create between representatives' action and their constituents' will. In that process, information is a key elementinformation about politicians' former behavior, about their programmes, about public agenda. A wide literature had discussed the influence of the main providers of information in contemporary societies (the mass media) on the relations between representatives and constituents. But Brazilian political field has peculiarities that put international literature in perspective.
\end{abstract}

Keywords: political representation, mass media, elections, Brazilian politics. 
O título de "democracia" que as sociedades contemporâneas ocidentais gostam de ostentar carrega sempre um adjetivo implícito: "representativa"1. A inevitabilidade da representação política coloca uma série de desafios à realização da democracia, compreendida em seu sentido etimológico, histórico e normativo de "governo do povo". Todos se referem, de uma forma ou de outra, a um mesmo problema. Uma vez que o povo de fato não governa, como garantir que sua vontade ou seus interesses sejam respeitados por aqueles que têm o poder efetivo de tomar as decisões? Como fazer com que a titularidade da soberania, atribuída ao povo, seja mais do que mera retórica consoladora, colocada no início dos textos constitucionais?

Para uma parte da teoria da democracia, aquela que se inspira mais diretamente nas formulações de Joseph Schumpeter, tal questão não se coloca. 0 povo, considerado incapaz de apreciação racional das questões públicas, não possui vontade, nem interesses. A democracia concorrencial assume, assim, um valor apenas instrumental; serve para produzir governantes legítimos e, portanto, reduz os custos da dominação política - já que os governados, ao votarem, acreditam que estão exprimindo sua vontade. De resto, a minoria toma as decisões, sem consultar o povo, o que, aliás, seria ocioso, já que suas opiniões, voláteis e infundadas, nada acrescentariam.

Para aqueles que, ao contrário, julgam que a democracia representativa pode estar dotada de alguma substância, o problema da relação entre as decisões dos governantes e a vontade popular é dos mais importantes. Nos regimes contemporâneos que são correntemente considerados democráticos, o principal mecanismo para garantir que os representantes levem em conta as preferências de seus constituintes é a realização periódica de eleições. Portanto, a qualidade do vínculo eleitoral - a capacidade que o processo eleitoral tem de vincular as ações dos representantes à vontade dos representados - é determinante da qualidade da democracia enquanto tal, isto é, enquanto governo do povo.

São muitos os obstáculos a serem vencidos para o aprimoramento do vínculo eleitoral. Há, por um lado, em todos os regimes eleitorais, em maior ou menor grau, o desinteresse de boa parte da população pelas questões públicas, o que se deve, ao menos em parte, ao fraco incentivo à educação política gerado pela participação restrita ao voto. A apatia pode ser, como quiseram alguns, benéfica para a

\footnotetext{
1 Este trabalho faz parte da pesquisa "Modelos alternativos de representação política", apoiada pelo Conselho Nacional de Desenvolvimento Científico e Tecnológico (CNPq) com uma bolsa de Produtividade em Pesquisa. Uma primeira versão do texto foi apresentada no GT "Eleições, valores e comportamento político" do XI Congresso Brasileiro de Sociologia (Campinas, 1 a 5 de setembro de 2003). Agradeço os comentários e as sugestões do parecerista anônimo de Opinião Pública e, também, de Regina Dalcastagnè.
} 
estabilidade dos governos (LIPSET, 1963 [1960]; ALMOND e VERBA, 1965 [1963]; HUNTINGTON, 1975), mas é negativa para o exercício da soberania popular. Sobretudo, quando se sabe que ela não é uma preferência individual entre outras alguns gostam de política, outros não - mas, ao contrário, está concentrada em alguns segmentos da população, como os trabalhadores braçais, as pessoas com menor escolaridade, as minorias étnicas e as mulheres.

Um segundo obstáculo é a tendência que os representantes têm de desenvolver interesses próprios, ligados às posições de poder que ocupam - aquilo que Robert Michels (1982 [1914]) descreveu, com perspicácia, mas também com algum exagero, como sendo a "lei de ferro da oligarquia". Mais grave ainda é a influência superior que alguns grupos especiais possuem sobre os tomadores de decisão. Esta influência é exercida, sobretudo, pelos detentores do capital, que mantêm o Estado numa relação de dependência estrutural, já que têm a capacidade de determinar o nível do investimento produtivo e, em conseqüência, da arrecadação tributária (OFFE, 1984 [1972]). E, além disso, possuem atrativos nada desprezíveis para os políticos, na condição de potenciais financiadores de campanha.

Meu foco aqui é num quarto obstáculo ao aprimoramento do vínculo eleitoral: o fluxo de informações. De forma um tanto esquemática, é possível dizer que, para que o eleitor seja capaz de fazer uma opção consciente, ele precisa estar provido de informações adequadas sobre: (a) quem são os candidatos, quem os apóia, quais são as suas trajetórias e as suas propostas; e (b) o mundo social, isto é, quais são os desafios a serem enfrentados, as alternativas possíveis e suas conseqüências. 0 adjetivo "adequadas", na frase anterior, costuma ser lido como "verdadeiras". No entanto, para a maior parte dos casos relevantes, o valor de verdade é discutível. 0 que está em jogo são os princípios de percepção do mundo político e social, envolvendo crenças, valores e convicções. Os fatos não precisam apenas ser apresentados, eles precisam ser interpretados, encaixados em narrativas dotadas de poder explicativo, ter seu peso relativo avaliado. Embora falsificações possam e devam ser coibidas, o que caracteriza a informação adequada para uma sociedade democrática é, acima de tudo, seu caráter plural. As diferentes perspectivas e visões de mundo devem estar disponíveis para o conjunto de cidadãs e cidadãos.

Nas sociedades contemporâneas, o provimento de informações sobre o mundo é tarefa de sistemas específicos, que formam o jornalismo, entendido aqui em sentido amplo (a imprensa escrita, mas também a divulgação de notícias por outro meios, como rádio, televisão ou internet). Em pequenas comunidades autárquicas, é possível imaginar que cada pessoa obtenha todas as informações significativas de que precisa para tocar sua vida através de sua vivência cotidiana ou do contato pessoal com testemunhas. No entanto, à medida em que esta sociedade cresce e que amplia suas trocas com comunidades próximas (e remotas), 
as informações significativas deixam de estar diretamente disponíveis. E a partir do momento em que aumenta o dinamismo desta sociedade, com o abandono de práticas tradicionais, cada indivíduo passa a precisar de um volume maior de informação.

O jornalismo supre esta necessidade; dito de forma sintética, o trabalho jornalístico consiste em recolher informações dispersas (através de uma rede de repórteres), "empacotá-las" através de determinados processos técnicos (jornal, rádio, televisão) e, enfim, distribuir o produto final a uma audiência diversificada. Para entender a relação entre este produto e seu público, é útil introduzir uma categoria de Giddens (1990), o "sistema perito" (expert system) ${ }^{2}$. Trata-se de um sistema de competência técnica especializada, do qual as pessoas em geral se servem, mas não são capazes de compreender seu funcionamento ou avaliar a priori sua eficácia.

Assim, o sistema perito exige, da parte de seus clientes ou consumidores, a confiança em sua competência específica. É o caso do jornalismo. O consumidor de informação que lê um jornal ou assiste a um noticiário não tem, via de regra, como checar se determinada sessão do Congresso realmente ocorreu, com tais e quais decisões sendo tomadas, ou se um navio realmente naufragou na costa da África. Ele confia no jornal ou no noticiário. Esta incapacidade de comprovação independente é tão acentuada que chega a particularizar o jornalismo dentre os diversos sistemas peritos. Quando alguém sobe num avião, está confiando nos saberes especializados de engenheiros e mecânicos que aquela aeronave materializa. Mas esta confiança está ancorada na experiência vivida, por ele ou por seus conhecidos, de viajar de avião e chegar ao destino. No caso do jornalismo, na maior parte das vezes, esta possibilidade não existe. A confirmação da confiança que se concede a um determinado noticiário não é dada pela vivência, mas pelos noticiários concorrentes, que apresentam conteúdo similar.

A crença depositada no jornalismo pelo consumidor de informações pode ser desdobrada em três elementos. Primeiro (e mais simples), a confiança na veracidade dos fatos relatados. Depois, a confiança de que realmente os aspectos mais relevantes de cada fato são aqueles que estão relatados. Por fim, a confiança na escolha acertada, entre a infinidade de eventos que ocorrem a cada dia, de quais mereceriam ser alçados à condição de "fatos jornalísticos". A imprensa possui, assim, o monopólio da seleção da notícia. O relevante é observar que este recorte da realidade, resultante das decisões de um grupo restrito de profissionais e submetido aos constrangimentos próprios do campo jornalístico, é apresentado à sociedade como sendo "a" realidade ou, ao menos, sua parcela significativa.

\footnotetext{
2 Para a aplicação à mídia, ver Miguel (1999a).
} 
$\mathrm{Na}$ próxima seção, analiso algumas das principais correntes teóricas que discutem o problema do provimento de informações (ou da mídia) para a ação política e, em particular, para a decisão eleitoral. Em seguida, discuto - de maneira ainda preliminar, uma vez que se trata de uma pesquisa em andamento - até que ponto a literatura internacional, produzida tendo em vista a realidade européia e, sobretudo, estadunidense, ilumina a vida política brasileira, cujas particularidades precisam ser levadas em conta.

\section{Correntes teóricas}

Quem quer que estude o impacto social dos meios de comunicação de massa está familiarizado com a narrativa da transição de uma perspectiva que via a mídia como quase onipotente para outra, chamada de "efeitos limitados", que reduziu brutalmente o alcance presumido de sua influência. A primeira, surgida nas décadas iniciais do século XX e associada ao nome de Harold Lasswell, vê o usuário da mídia como consumidor passivo, um teleguiado, que reproduz de forma automática aquilo que os meios transmitem. A pesquisa posterior desacreditou uma percepção tão simplista, observando que as pessoas que consomem as visões de mundo produzidas pela mídia também as reinterpretam de diferentes maneiras, de acordo com seus backgrounds, tradições, influências de outros aparelhos ideológicos etc. No entanto, como será visto adiante, perspectivas similares à de Lasswell reaparecem, por vezes, no debate sobre mídia e política.

É mais importante a segunda corrente, dos "efeitos limitados", nascida com as pesquisas de Paul Lazarsfeld e seus associados sobre o comportamento dos eleitores nos Estados Unidos. Tais estudos, produzidos nos anos 1940 e 1950, entre os quais se destacam The people's choice (LAZARSFELD, BERELSON e GAUDET, 1969 [1944]) e Voting (BERELSON, LAZARSFELD e MCPHEE, 1954), logo ganharam - e por muitos títulos - o estatuto de clássicos. São pioneiros da sociologia eleitoral, com uso inovador, para a época, de técnicas de sondagens de opinião e de tratamento estatístico dos dados. Em relação aos meios de comunicação de massa, as principais contribuições são a teoria do fluxo comunicacional em duas etapas (two-step flow of communication) e uma redução brutal da influência atribuída à mídia.

De acordo com os dados de Lazarsfeld e equipe, a informação disseminada pela mídia atinge um pequeno número de pessoas, que depois a transmitem para os outros. Existe, portanto, um grupo crucial de intermediários, que filtra a comunicação. Mais tarde, a teoria do two-step flow vai incorporar novos elementos, afirmando que existem inúmeros diferentes grupos de "líderes de opinião", conforme as diferentes áreas de interesse (política, esportes, negócios, moda, 
cinema) (KATZ E LAZARSFELD, 1964); a utilização que se tornou corrente, porém, é a que separa um núcleo de "formadores de opinião" do restante da população.

Quanto ao impacto da mídia no comportamento dos eleitores, os estudos de Lazarsfeld e seus associados procuram minimizá-lo, fazendo sobressair a importância do meio social, que seria o motivador preponderante do voto e, por extensão, de todas as formas de adesão política. Mulheres e homens seguiriam um comportamento de tipo mimético, reproduzindo as atitudes e as opiniões de seus familiares, colegas de trabalho, vizinhos e amigos. O efeito da campanha eleitoral e, de forma mais ampla, de toda a informação veiculada pelos meios de comunicação fica reduzido à ativação e ao reforço de inclinações latentes. De acordo com uma das metáforas exploradas em The people's choice, seria uma situação análoga à de uma criança que coloca uma moeda sob uma folha de papel e em seguida passa sobre ela um lápis de cera: sem sua ação, não surgiria nenhuma imagem, mas, ao mesmo tempo, ela não tem o poder de produzir qualquer imagem que não seja aquela que já se encontra gravada na face da moeda (LAZARSFELD, BERELSON e GAUDET, 1969 [1944], p. 75).

Ou seja, sem a presença de informação vinda de fora, a opinião não emergiria; mas a única opinião que ela é capaz de fazer brotar é aquela a qual o indivíduo já está predisposto, pela ação do meio social. Conteúdos que eventualmente contradigam tais disposições são em geral descartadas, graças ao fenômeno da "dissonância cognitiva", isto é, à tendência, que todas as pessoas têm, de rechaçar informações que se mostrem incompatíveis com suas crenças.

Os resultados obtidos pelos cientistas sociais liderados por Lazarsfeld, tão decepcionantes à primeira vista, serviram de estímulo para a pesquisa posterior a respeito da influência dos meios de comunicação sobre a sociedade e, em especial, sobre a política. Foram formulados modelos de trabalho mais sofisticados, deslocando a ênfase dos efeitos de curto prazo para efeitos a longo prazo, cumulativos, produzidos pela mídia. O foco sobre a produção da agenda pública, com a chamada "hipótese do agenda-setting" e conceitos relacionados (priming, framing etc.), contribuiu para iluminar dimensões antes ocultas da relação entre mídia e política.

Apresentada por McCombs e Shaw (1972), a hipótese do agenda-setting desenvolve a idéia de que os meios de comunicação de massa, mais do que determinar o que o público pensa, têm um papel crucial na indicação de quais são os temas importantes do momento, influenciando tanto os cidadãos comuns quanto o governo e a elite política. Inspirado na obra do sociólogo Erving Goffman (1974), o conceito de framing acrescenta que o relato dos fatos sempre está embutido em narrativas explicativas implícitas, que contribuem para modelar a visão de mundo das audiências. E o conceito de priming aponta que o noticiário afeta o julgamento sobre os líderes políticos, na medida em que os cidadãos tendem a dar maior peso 
aos assuntos que encontram maior destaque na agenda pública (IYENGAR, 1991, p. 133).

Assim, no cômputo geral, os estudos dos anos 1940, em que pesem seus vários insights e as muitas contribuições de ordem metodológica, podem ser considerados como superados. Mas, ainda que os resultados de tais estudos fossem aceitos sem ressalvas, seria necessário observar que ao menos os líderes dos diversos grupos sociais faziam suas escolhas a partir do contato com as informações recebidas pela mídia - conforme postula a teoria do two-step flow. Se a tendência daquele grupo por um dado movimento político é "tradicional" e atravessa gerações, mesmo assim houve algum momento em que essa inclinação se cristalizou - sem dúvida, por influência do discurso político, que, aliás, permanece atuando como fator de reforço da adesão. Ainda que se imagine que as condições sociais objetivas levam à adesão a determinado tipo de movimento político, a identificação do líder ou movimento que elas exigem dependeria das mensagens políticas por ele expostas e acessíveis ao público. Afinal, para usar o exemplo mais óbvio, a classe operária só pode identificar o "seu partido" caso este assim se proclame diante dela. Portanto, as condições sócio-culturais do indivíduo e a oferta disponível no mercado político (isto é, acessível ao público) formam os elementos fundamentais da adesão política, sem que seja factível hierarquizá-los.

Os estudos do grupo de Lazarsfeld são céticos em relação à possibilidade de melhoria substancial da democracia, na medida em que fazem um retrato do eleitor como sendo, por natureza, apático, desinteressado e desinformado. De maneira não programada, serviram de confirmação empírica às teses que, na mesma época, Schumpeter estava veiculando. De acordo com esta perspectiva, os meios de comunicação de massa são um não-problema, já que os limites à democracia se encontram basicamente dentro de cada cidadão, nas suas limitações cognitivas e na miopia de suas preocupações, não na distribuição social de recursos (informacionais ou outros).

A percepção da mídia como não-problema está presente, de diferentes maneiras, na maior parte dos autores liberais. Muitos deles julgam que a livre competição no mercado supre a necessidade de difusão de informação, posição que é ilustrada de maneira exemplar na obra de Giovanni Sartori (antes que, com a publicação dos célebres artigos "Videopotere" e "Videopolítica", o cientista político italiano desse uma guinada drástica em sua avaliação do papel da mídia). Ele dedica umas poucas páginas de seu A teoria da democracia revisitada aos meios de comunicação de massa e à formação da opinião pública. Seus argumentos podem ser agrupados em duas vertentes complementares:

(1) a fórmula liberal do "livre mercado de idéia". A concorrência pelo mercado leva ao aumento da qualidade da informação apresentada ao público; afinal, "um sistema de informação semelhante ao sistema de mercado é um sistema de 
autocontrole, um sistema de controle recíproco, pois todo canal de informação está exposto à vigilância dos outros" (SARTORI, 1994 [1987], vol. 1, p. 140). Ou seja, se um jornal apresenta uma notícia falsa ou deixa de relatar algo que tenha relevância para seus leitores (ouvintes, telespectadores etc.), seus concorrentes irão denunciar a fraude ou a omissão, em busca de benefício próprio, mas atuando objetivamente em proveito do público;

(2) a crença na objetividade da informação. Àqueles que reclamam do reduzido pluralismo dos meios de comunicação nas democracias eleitorais contemporâneas, Sartori responde que a multiplicação dos canais aumentaria a quantidade de informações, mas não necessariamente "sua correção ou objetividade" (SARTORI, 1994 [1987], vol. 1, p. 143). Depreende-se que este último valor (correção ou objetividade) é o importante e sua garantia repousa não no acesso generalizado de todos à produção de informações, que representaria um gigantesco desperdício de recursos, mas numa "ética profissional" específica, de "respeito pela verdade" (SARTORI, 1994 [1987], vol. 1, p. 144).

As duas vertentes da argumentação são complementares porque a idéia do mercado que se autocontrola só faz sentido na medida em que se julga que o papel da mídia é prover "informação verdadeira". Uma vez que o produto a ser difundido é, na essência, o mesmo, o pluralismo possui valor apenas instrumental, é necessário para evitar desvios por parte dos produtores. A crítica feita ao "mercado de idéias" envolve a compreensão de que está em jogo mais do que a correção factual; estão em jogo valores, perspectivas sociais, visões de mundo. Quando a comunicação se processa de acordo com mecanismos de mercado, seus provedores - na condição de empresas - tendem a esposar posições similares, algo que já era apontado, nos anos 1940, pelo próprio Lazarsfeld (1978 [1948]) . $^{3}$.

Quanto maior a polaridade política, mais claros os limites da concorrência mercantil como instrumento de pluralismo da mídia. Nos Estados Unidos, onde o debate público, nos termos colocados pelos dois grandes partidos, se dá sobre um leque muito reduzido de alternativas, é possível dizer que os meios de comunicação reproduzem razoavelmente bem o curto espectro político relevante. O mesmo não se poderia dizer de países da Europa Ocidental, quando os partidos comunistas possuíam lastro eleitoral; nem do Brasil, durante o período em que o Partido dos Trabalhadores era visto como força anti-sistêmica (MIGUEL, 2003).

Uma variante engenhosa da percepção liberal é encontrada na obra de Anthony Downs (1957). De acordo com ele, não é exatamente a competição no mercado da mídia que resolve o problema da informação política, mas a competição

\footnotetext{
${ }^{3}$ A pesquisa crítica sobre mídia tem enfatizado o impacto do controle da propriedade; ver, entre muitos outros, Entman (1989), McChesney (1997) e Bagdikian (1997).
} 
eleitoral. Cada partido ou candidato possui interesse em divulgar ao máximo informações que sejam favoráveis a si ou desfavoráveis a seus oponentes. Como resultado, os eleitores terão disponível, a baixo custo, uma quantidade razoável de informação relevante; terão disponível, em especial, o contraditório político, já que estarão submetidos a versões divergentes sobre o que é a realidade social, quais os problemas mais candentes e suas soluções, quem são os agentes políticos, quais os seus compromissos. Downs reconhece a disparidade de recursos informacionais detidos pelos diferentes cidadãos, mas tende a julgar que se trata mais de um efeito das características do público (alguns indivíduos têm maior capacidade de apreensão de informações do que outros) do que da oferta. Na economia geral de sua teoria, fortemente ancorada numa idéia de transparência do mundo para os agentes que o vivem, tal desigualdade não constitui um problema sério.

O modelo de Downs pressupõe a existência de um quadro partidário razoavelmente sólido, já que os partidos suprem a tarefa crucial de sinalizar o espaço político, permitindo que os eleitores nele se situem mesmo quando possuem reduzida informação. No entanto, um dos efeitos mais citados dos meios de comunicação - em especial eletrônicos - é a personalização das disputas políticas. Partidos, bem como outros tipos de associações e movimento coletivos, são abstrações. Só por uma ficção, que o jornalismo impresso podia sustentar, mas a televisão não, um partido se dirige ao público. Na realidade, ele sempre necessita de porta-vozes. À medida em que a visibilidade destes porta-vozes aumenta, eles tendem a ocupar o espaço das organizações coletivas (GITLIN, 1980). A política, então, é cada vez mais vista como uma disputa entre personalidades; mais importante, o eleitor tende a julgar os políticos por critérios de personalidade (KEETER, 1987).

Os meios de comunicação de massa, assim, vão desempenhar um papel significativo naquilo que Martin Wattenberg (1998) chamou de "declínio dos partidos políticos". Não apenas as personalidades se sobrepõem às organizações, como também o acesso ao eleitorado prescinde da estrutura partidária: uma rede de comitês de militantes era importante quando se tratava de distribuir santinhos, não quando se faz uma transmissão em cadeia nacional.

Entre as obras influentes da ciência política mais recente, o papel da mídia em substituição aos partidos é enfatizado sobretudo por Bernard Manin (1997). Segundo ele, os regimes representativos ingressaram, a partir de meados do século XX, numa terceira fase. Após um período inicial de "parlamentarismo", em que os representantes eram notáveis locais, escolhidos em eleições que espelhavam relações pessoais de confiança, e um período intermediário de "democracia de partidos", expressão de uma política de classes, chegava-se à "democracia de audiência". 
Nela, o processo eleitoral volta a indicar uma confiança pessoal, mas agora refletindo as imagens construídas na mídia, não os vínculos locais. Na democracia de audiência, as pesquisas de opinião e os especialistas na construção de imagens ocupam posições de protagonistas, os partidos perdem importância e o eleitor se torna disponível para o mercado político como um todo, uma vez que as lealdades tradicionais entram em declínio.

Embora Manin apresente uma tese bem embasada, repleta de insights estimulantes, que coroa um livro que já se inscreve entre as obras fundamentais para o estudo da representação política, e ainda que suas fases do governo representativo sejam entendidas como "tipos ideais", a relação entre mídia e política peca por seu simplismo. É difícil negar que o campo da mídia exerce profunda influência sobre o campo político e modificou o comportamento dos eleitores, mas não se deve ignorar que não há nada semelhante a uma "colonização" da política pela mídia. As relações entre os dois campos são de mão dupla; a política não apenas retém algumas especificidades nada desprezíveis - até porque nem toda a política se faz aos olhos do público - como também influencia a própria mídia (MIGUEL, 2002).

Os estudos que incorporam elementos da sociologia do jornalismo tendem a apresentar narrativas mais complexas. Nos anos 1970, escritos seminais de Gaye Tuchman e outros abriram importantes vias de investigação sobre o mundo da imprensa, avançando além de obras anteriores, de caráter ensaístico e impressionista, mesmo que inspiradas (e inspiradoras), como o muito citado livro de Daniel Boorstin (1992 [1962]). Em especial, Tuchman apontou dois elementos do impacto das rotinas produtivas da imprensa sobre a confecção do noticiário: a "ritualização" do valor da objetividade, que deixa de se referir ao mundo objetivo e se reduz à obediência a determinadas estratégias (ouvir os dois lados, atribuir as informações a fontes identificáveis); e a organização de estruturas mentais que antecipam o que deve ser notícia, conciliando o que deveria ser o trabalho do repórter (a busca do inesperado) com a produção industrial rotinizada do jornalismo (TUCHMAN, 1972; TUCHMAN, 1973; ver tb. FISHMAN, 1980).

Os estudos de sociologia do jornalismo embasaram a crítica à cobertura eleitoral realizada pela mídia, sintetizada na expressão "cobertura tipo corrida de cavalos (horse-race)", que se interessa apenas pela posição relativa dos candidatos na disputa, não por seus programas e idéias. De acordo com a definição de um autor:

“Um cavalo não é julgado por sua velocidade ou talento absolutos mas em comparação com a velocidade de outros cavalos, e em especial por suas vitórias e derrotas. Similarmente, candidatos são levados a discutir outros candidatos; eventos são entendidos num contexto de competição; e indicar o vencedor se torna um tópico importante. A 
corrida, não o vencedor, é a história. A imagem, a personalidade, a equipe e a estratégia do candidato são os focos principais da reportagem" (BROH, 1980, p. 515).

Assim, o resultado das sondagens de opinião pública torna-se o interesse principal da cobertura da campanha. Todos os discursos e movimentos dos candidatos, de seus aliados, dos partidos ou do governo perdem o interesse intrínseco que poderiam ter e tornam-se imediatamente alvo de especulação quanto ao impacto que terão na preferência popular. O aspecto desportivo da cobertura, que a aproxima de um modelo conhecido, torná-la-ia mais atraente para o consumidor de informação comum, despreparado para o debate sobre temas substantivos da agenda pública.

Uma apresentação bem mais sofisticada do tema da horse-race aparece na tese da "espiral do cinismo", desenvolvida por Joseph Cappella e Kathleen Hall Jamieson (1997). A imprensa não apenas apresenta a campanha eleitoral no formato da corrida de cavalos, para torná-la mais acessível ao público; esta apresentação é efeito da leitura que os profissionais do jornalismo fazem do mundo político, uma leitura cínica, que julga que os líderes políticos estão preocupados apenas com a manutenção ou ampliação do próprio poder. Os jornalistas acham que os políticos tudo reduzem à estratégia eleitoral, isto é, programas, compromissos e promessas não passam, no final das contas, de mera manipulação. A cobertura reflete esta crença comum àqueles que fazem a imprensa.

Trata-se de uma "espiral" porque a visão de mundo transmitida pelo jornalismo induz os políticos e o público a comportamentos que reforçam esta leitura cínica. Os políticos logo percebem que não vale a pena investir suas energias na discussão dos temas substantivos, já que isso não terá repercussão midiática - e será visto com desconfiança pelo público, que absorve a visão da política que recebe dos noticiários. Na perspectiva de Cappella e Jamieson, o vilão é o jornalismo. Sem seu cinismo, as virtudes dos homens públicos emergiriam, a qualidade do debate político melhoraria e até o nível de conflito seria reduzido, conforme é insinuado pela história da conversa construtiva entre o presidente Bill Clinton (democrata) e o líder republicano Newt Gingrich, que abre o livro.

A tese de Cappella e Jamieson denuncia o jornalismo em geral. Muitos outros estudos escolhem por alvo a televisão. É o caso de dois cientistas sociais europeus importantes, situados em pólos opostos do espectro político, que julgam - por diferentes motivos - que a televisão está corrompendo a vida política. Um deles é Giovanni Sartori, que pouco após desprezar a importância da mídia, no tratado de teoria democrática antes citado, converteu-se à visão de que a televisão está comprometendo o processo democrático, publicando um artigo muito citado (em duas versões, "Videopotere" e "Videopolitica", que correspondem praticamente ao mesmo texto) e em seguida o livro Homo videns. 
Sartori parte da tese de que a imagem é inimiga da abstração. Logo, a televisão, que substitui o inteligível pelo visível, está produzindo uma geração de débeis mentais, incapazes de raciocínio lógico. As conseqüências desta transformação seriam as mais profundas (e nefastas) possíveis, tanto na política, que merece atenção especial do autor, quanto na cultura, na educação e na ciência. O cientista político italiano toca em questões importantes, mas seu argumento peca por graves deficiências. Em primeiro lugar, pela dicotomia simplista entre palavra e imagem. Para ele, a comunicação verbal é constituída de códigos, mas a visual não: "a imagem é pura e simples representação visual" (SARTORI, 1998 [1997], p. 35). A linguagem da televisão deixaria de ser uma linguagem; seria uma mera cacofonia de imagens. Sartori se mostra incapaz de apreender o caráter simbólico da comunicação visual, que julga privilégio da comunicação verbal.

Segundo Sartori, a influência dos governados sobre os governantes é a influência da opinião pública (que se expressa através das eleições). O problema apresentado em Homo videns é que, na era da videopolítica, esta opinião é manipulada. Tal manipulação se torna ainda mais poderosa graças à influência das sondagens de opinião pública, que recolhem pareceres voláteis, simples reflexos do que sustentam os meios de comunicação, e os transformam em elemento essencial para as decisões governamentais. Há aqui, segundo Sartori, um transbordamento da esfera legítima da influência popular sobre o governo, que é o processo eleitoral. Através das sondagens, a opinião do povo, pouco informada e, além do mais, forjada, passa a influir em decisões que deveriam ser tomadas por profissionais "cognitivamente competentes", os políticos (SARTORI, 1998 [1997], p. 126).

Ao introduzir o problema da manipulação da opinião pública, Sartori dá um importante passo à frente em relação a $A$ teoria da democracia revisitada, onde negava explicitamente que os meios de comunicação constituíssem uma questão política relevante. Em Homo videns, ao contrário, ele admite que a concorrência comercial na mídia gera mais uniformidade do que diversidade. Mas o passo à frente de Sartori é limitado. Em primeiro lugar, ele não vai além de um superado modelo de estímulo/reação mecânicos, tributário das pesquisas já quase centenárias (e superadas) de Lasswell, que lhe permite afirmar que "atualmente, o povo soberano "opina' sobretudo em função de como a televisão o induz a opinar" ou, então, que a opinião pública é apenas o "eco" da televisão (SARTORI, 1998 [1997], p. 66 e 72). Em segundo lugar, Sartori advoga a idéia de que a TV deforma a opinião pública por uma espécie de tara de origem (a "imagem inimiga da reflexão"), ignorando por completo a questão chave, que é o controle dos meios de comunicação. O resultado é a idéia, um tanto bizarra, de uma manipulação sem objetivos, que não serve a nenhum grupo, a nenhum interesse, fruto apenas das patologias do tubo de imagem. 
O outro cientista social europeu a estudar o tema é Pierre Bourdieu, que dedicou a ele um livrinho de intervenção, Sur la télévision (1996). Seu objetivo era alertar para o peso excessivo dos meios comunicação de massa na formação das reputações políticas e universitárias, comprometendo a autonomia dos campos político e acadêmico. Fora alguns insights estimulantes, pouco há, no livro, que avance para uma compreensão mais sistemática da relação entre mídia e política como campos relativamente independentes, na medida em que retêm sua própria lógica, mas sobrepostos, já que interferem, em larga escala, um no outro ${ }^{4}$. Apesar dos valores políticos democráticos e radicais que sustenta, opostos ao elitismo de Sartori, Bourdieu apresenta a mesma intenção do cientista político italiano: denunciar a presença ilegítima da televisão em nome dos "bons tempos" passados, em que a política se desenrolava sem a presença dela.

\section{O ideal ausente}

Do sobrevôo aqui realizado, por diferentes correntes teóricas, uma constatação se impõe. Se o peso atribuído aos meios de comunicação de massa nos processos políticos e eleitorais é maior do que zero, então eles inevitavelmente aparecem como "intrusos", em contraste com uma norma de funcionamento da democracia, implícita ou explicitada. Esta norma coloca os partidos em uma posição de absoluta centralidade, como intermediários indispensáveis do jogo político, agregando interesses, canalizando demandas e produzindo a adesão eleitoral.

No caso do Brasil, cabe lembrar que esta norma nunca se concretizou. Isto é, a vida política brasileira jamais se estabeleceu de acordo com o ideal do sistema representativo-partidário ${ }^{5}$; os meios de comunicação não aparecem como acréscimos posteriores desorganizando algo que se encontrava próximo de um funcionamento ideal. Quatro peculiaridades devem ser observadas, dadas as repercussões que possuem: (1) o sistema eleitoral; (2) a volatilidade do regime de partidos; (3) a concentração da mídia; (4) o peso diferenciado da televisão na sociedade brasileira.

\footnotetext{
${ }^{4}$ Colaboradores de Bourdieu, como Patrick Champagne, Rémi Lenoir e Louis Pinto, têm produzido um conjunto de obras sobre os meios de comunicação franceses, mas com abordagem mais próxima à sociologia do jornalismo. Para uma resenha desta literatura, ver Benson (1998). Apresentei anteriormente uma tentativa de incorporação das categorias de Bourdieu num modelo mais complexo das relações entre a mídia e a política (MIGUEL, 2002).

5 Há uma vasta literatura sobre o tema, a partir das obras pioneiras de Soares (1973) e Souza (1976). Diagnósticos recentes sobre os problemas do sistema partidário brasileiro encontram-se em Lima Jr. (1997, p. 111-28) e Reis (2000). Para uma resenha da literatura, ver Lima Jr. (1999).
} 
Quanto ao item (1), o Brasil adota o sistema de representação proporcional com listas abertas; um dos efeitos de tal sistema, amplamente anotado pela literatura, é o estímulo à competição intrapartidária nas eleições legislativas. Cada candidato, assim, possui seu próprio comitê, sua própria campanha e seus próprios apoiadores; precisa se diferenciar de todos os seus concorrentes, aí incluídos os próprios correligionários. Ou seja: a personalização da política, no Brasil, é efeito do próprio sistema eleitoral. Aos meios de comunicação de massa caberia, quando muito, um papel secundário.

A volatilidade do regime de partidos, que corresponde ao item (2), está estreitamente ligada aos efeitos do sistema eleitoral. As listas abertas debilitam as direções partidárias, incapazes de hierarquizar os candidatos; além disso, fazem com que as votações sejam patrimônio pessoal dos candidatos, que assim ganham em poder de barganha e em mobilidade, ou seja, podem transitar de uma legenda para outra esperando carregar consigo seu contingente de eleitores. Outros fatores contribuem para o enfraquecimento dos partidos, em especial as regras extremamente permissivas para coligações eleitorais, mesmo em eleições proporcionais: a baixa exigência de filiação partidária para candidaturas e a ausência de imposição legal de fidelidade partidária no exercício do mandato parlamentar 6 .

O resultado é que os partidos brasileiros são muito fracos, ainda que estudos recentes tentem relativizar tal constatação ${ }^{7}$. São fracos porque sua ação no parlamento tende a ser fragmentada e também porque - o que é mais importante no contexto desta discussão - amealham pouca lealdade entre o eleitorado. As legendas partidárias não são importantes para a elite política, que se utiliza delas conforme as conveniências de momento, nem para uma grande fração do público, que não se preocupa com elas na hora de fazer sua opção eleitoral. A exceção sempre apontada, no Brasil pós-redemocratização, é o Partido dos Trabalhadores que, no entanto, está enfrentando mal o teste do exercício do poder. Fica claro que o enfraquecimento dos partidos não é efeito da mídia e sim de variáveis institucionais de longo curso no país.

\footnotetext{
6 Para evitar qualquer mal-entendido, esclareço que não compartilho da crença - disseminada entre cientistas políticos - de que o fortalecimento do sistema partidário é um benefício inequívoco e sem contra-indicações. Partidos mais fortes também podem significar menos autonomia para os eleitores, menor responsividade dos representantes para com seus constituintes e o engessamento do jogo político.

7 Estou me referindo a trabalhos como os de Figueiredo e Limongi (2002), que dão maior destaque aos partidos para a compreensão do funcionamento do poder legislativo.
} 
Assim, no Brasil, a mídia intervém num campo político que guarda profundas diferenças com o cenário, real ou idealizado, das democracias eleitorais no mundo desenvolvido. Ao mesmo tempo - e entro agora no terceiro item - os meios de comunicação brasileiros vivem uma situação de semi-monopólio privado que se diferencia de outros países. A Rede Globo detém mais da metade da audiência superando os $70 \%$ no chamado "horário nobre" - e mais de três quartos da verba publicitária da televisão brasileira; está presente também, com força, em todas as principais praças de rádio, na mídia impressa (jornais e revista), TV por assinatura, cinema e internet. Apenas como contraponto, nos Estados Unidos, apesar da tendência a fusões do mercado de mídia, na última década pulverizou-se a audiência da televisão aberta, com o surgimento de uma quarta competidora (a Fox) num cenário antes dominados por três grandes redes (CBS, ABC e NBC). Na maior parte dos países da Europa Ocidental, a audiência da emissora líder gira em torno dos $30 \%$, podendo chegar a tão pouco quanto os $16 \%$ da Alemanha (NORRIS, 1999, p. 95-6, a partir de dados da UNESCO).

Isto significa que, no Brasil, os efeitos benéficos derivados da competição mercantil na comunicação - que já são, conforme visto, intrinsecamente limitados pouco se realizam. Em diversos episódios da história recente do país, incluindo claramente as três primeiras eleições diretas para a presidência da República após a redemocratização, a Rede Globo pôde utilizar seus noticiários com intenção expressa de influir no quadro político. Graças à sua posição semi-monopolística, os ônus sofridos foram relativamente pequenos (MIGUEL, 1999b).

É importante observar, aqui, uma característica específica do Brasil (e de outros países da América Latina): a combinação entre a grande penetração da mídia eletrônica de massa, em níveis que se aproximam aos dos países desenvolvidos, com a precária cobertura da escola, que muitas vezes cumpre mal sua tarefa de socialização de conhecimentos e exclui um largo contingente da população - o item (4) das peculiaridades listadas acima. No mundo desenvolvido, a penetração da mídia eletrônica é gigantesca, mas a escolaridade é alta e o analfabetismo, quase inexistente. Em muitos países africanos e asiáticos, a cobertura escolar é precária, mas o rádio e, sobretudo, a televisão ainda são raros. O Brasil combina aspectos destas duas realidades. A escola é deficiente, tanto na cobertura da população, quanto em sua tarefa de socialização de conhecimentos. O analfabetismo atinge $20 \%$ dos adultos, segundo o censo de 1991 , número ao qual devem ser somados os muitos "analfabetos funcionais", que freqüentaram a escola apenas para aprender a desenhar o próprio nome e são incapazes de absorver informações a partir de um texto escrito. Mas a televisão atinge a população num índice comparável ao de países da Europa ocidental: de acordo com a Pesquisa 
Nacional por Amostra de Domicílios do IBGE, em 2001, 89\% das moradias possuíam televisão e $88 \%$, rádio (IBGE, 2001) ${ }^{8}$. Por outro lado, a tiragem somada dos principais jornais não alcançava 1 milhão de exemplares no final dos anos 1980, isto é, equivalia a menos de $1 \%$ da população (CONTI, 1999, p. 247).

Tabela 1

Tipos de público, de acordo com a penetração da mídia e a escolarização

\begin{tabular}{|l|l|l|}
\hline & alta escolaridade & baixa escolaridade \\
\hline alta penetração da mídia & $\begin{array}{l}\text { I público informado com } \\
\text { potencial crítico: } \\
\text { Europa (hoje) }\end{array}$ & $\begin{array}{l}\text { III - público dependente da } \\
\text { mídia: } \\
\text { Brasil }\end{array}$ \\
\hline baixa penetração da mídia & $\begin{array}{l}\text { II - público escolarizado em IV - público tradicional (ou } \\
\text { redes tradicionais: } \\
\text { Europa (início do século XX) }\end{array}$ & $\begin{array}{l}\text { ausência de público): } \\
\text { África }\end{array}$ \\
\hline
\end{tabular}

A tabela acima apresenta quatro tipos de público, segundo a penetração da mídia eletrônica e o nível de escolarização. O modelo normativo implícito na maior parte dos estudos que vêem a mídia como "intrusa" no jogo político é o número II, correspondente a sociedades pré-midiáticas que já haviam alcançado a universalização da escola, ou algo próximo disto. Era a situação dos países mais avançados na Europa ocidental nas primeiras décadas do século XX, mas hoje não corresponde a nenhum caso. Embora o consumo de mídia eletrônica varie bastante de país para país, chegando a níveis relativamente baixos em alguns deles, como a Holanda, em todos os países da Comunidade Européia, bem como nos Estados Unidos, o noticiário de televisão é uma fonte de informações mais importante do que os jornais impressos ${ }^{9}$.

Em sociedades do tipo III, como o Brasil, é evidente que existem limitações estruturais à difusão da mídia impressa, dada a fraca alfabetização. Mais importante é o fato de que, como a cobertura escolar é precária - mesmo para aqueles que chegam à escola - os meios de comunicação de massa ocupam uma posição crucial não apenas na difusão de informações sobre os fatos correntes, mas também das informações que o sistema educacional deveria transmitir. Basta lembrar de como as telenovelas de época são significativas para a socialização de

\footnotetext{
8 Infelizmente, o relatório do IBGE não permite inferir quantas moradias possuem televisão e/ou rádio, um contingente que quase certamente ultrapassa os $90 \%$.

${ }^{9}$ Cf. a tabela em Norris (2000, p. 80), com dados do Eurobarômetro e, para os EUA, do National Election Survey.
} 
determinados conhecimentos a respeito da história do Brasil. Em suma, falta à sociedade de tipo III um diálogo minimamente equilibrado entre conhecimentos e valores socializados pela instituição escolar e aqueles que os meios de massa transmitem, diálogo este que existe nas sociedades de tipo I (com forte penetração da mídia, mas escolarizadas).

Ao escrever seu célebre tratado sobre os aparelhos ideológicos, no contexto europeu e na ressaca dos movimentos de maio de 1968, Althusser assinalava que "o aparelho ideológico de Estado que foi colocado em posição dominante nas formações capitalistas maduras [...] é o aparelho ideológico escolar" (ALTHUSSER, 1982 [1970], p. 105). Não cabe aqui discutir a validade da afirmação para a situação em que foi escrita, mas assinalar que, na América Latina e sobretudo no Brasil, a combinação de escola incipiente e mídia audiovisual disseminada faz dos meios eletrônicos de comunicação, em especial da televisão, o aparelho ideológico dominante.

Tomadas em conjunto, o que as quatro peculiaridades brasileiras significam? Creio que se impõem duas conclusões que, embora contraditórias em aparência, precisam ambas ser levadas em consideração pelos estudiosos dos processos políticos e eleitorais no país. A primeira é que a centralidade dos meios de comunicação eletrônicos no Brasil é maior do que no mundo desenvolvido. Por conta disso, os limites de receitas para uma mídia "boa para a democracia", como a prescrição liberal de concorrência mercantil, aparecem com maior clareza por aqui do que nos países centrais. A segunda é que os problemas que a literatura internacional atribui à influência da mídia, como o declínio dos partidos e a personalização da competição política, no caso brasileiro, encontram outras raízes, em especial as instituições políticas vigentes. 


\section{Bibliografia}

ALMOND, G. A. e VERBA, S. The civic culture: political attitudes and democracy in five nations. Boston: Little Brown, 1965 [1963].

ALTHUSSER, L. Idéologie et appareils idéologiques d'État. In: Positions. Paris: Éditions Sociales, $1982[1970]$.

BAGDIKIAN, B. H. The media monopoly. $5^{\mathrm{a}}$ ed., ampliada. Boston: Beacon Press, 1997.

BENSON, R. Field theory in comparative context: a new paradigm for media studies. Theory and Society, vol. 28, n 3. Dordrecht, p. 463-98, 1998.

BERELSON, B. R.; LAZARSFELD, P. F. e MCPHEE, W. Voting: a study of opinion formation in a presidential campaign. Chicago: The University of Chicago Press, 1954.

BOORSTIN, D. J. The image: a guide to pseudo-events in America. New York: Vintage, 1992 [1962].

BOURDIEU, P. Sur la télévision, suivi de L'emprise du journalisme. Paris: Liber, 1996.

$\mathrm{BROH}, \mathrm{C}$. A. Horse-race journalism: reporting the polls in the 1976 presidencial election. Public Opinion Quaterly, vol. 44, n 4. New York, p. 514-29, 1980.

CAPPELLA, J. N. e JAMIESON, K. H. Spiral of cynicism: the press and the public good. Oxford: Oxford University Press, 1997.

CONTI, M. S. Notícias do Planalto: a imprensa e Fernando Collor. São Paulo: Companhia das Letras, 1999.

DOWNS, A. An economic theory of democracy. New York: Harper \& Brothers, 1957.

ENTMAN, R. M. Democracy without citizens: media and the decay of American politics. Oxford: Oxford University Press, 1989.

FIGUEIREDO, A. C. e LIMONGI, F. Incentivos eleitorais, partidos e política orçamentária. Dados, vol. 45, n² 2. Rio de Janeiro, p. 303-44, 2002.

FISHMAN, M. Manufacturing the news. Austin: University of Texas Press, 1980. 
GIDDENS, A. The consequences of modernity. Stanford: Stanford University Press, 1990.

GITLIN, T. The whole world is watching: mass media in the making \& unmaking of the New Left. Berkeley: University of California Press, 1980.

GOFFMAN, E. Frame analysis: an essay on the organization of experience. New York: Harper \& Row, 1974.

HUNTINGTON, S. P. The United States. In: CROZIER, M. J.; HUNTINGTON, S. P. e WATANUKI, $\mathrm{J}$. The crisis of democracy: report on the governability of democracies to the Trilateral Comission. New York: New York University Press, 1975.

IBGE (Instituto Brasileiro de Geografia e Estatística). Pesquisa nacional por amostra de domicílios, 2001: síntese de indicadores. Brasília: IBGE, 2002.

IYENGAR, S. Is anyone responsible? How television frames political issues. Chicago: The University of Chicago Press, 1991.

KATZ, E. e LAZARSFELD, P. F. Personal influence: the part played by people in the flow of mass communications. New York: Free Press, 1964.

KEETER, S. The illusion of intimacy. Public Opinion Quarterly, vol. 51, n 3. Chicago, p. 344-58, 1987.

LAZARSFELD, P. F.; BERELSON, B. e GAUDET, H. The peoples's choice: how the voter makes up his mind in a presidential campaign. $3^{\text {a }}$ ed. New York: Columbia University Press, 1969 [1944].

LIMA JR., O. B. Instituições políticas democráticas: o segredo da legitimidade. Rio de Janeiro: Jorge Zahar, 1997.

Partidos, eleições e poder legislativo. In: MICELI, S. (org.). O que ler na ciência social brasileira (1970-1995), v. 3. São Paulo: Sumaré, ANPOCS, 1999.

LIPSET, S. M. Political man: the social bases of politics. Garden City: Anchor Books, 1963 [1960].

MANIN, B. The principles of representative government. Cambridge: Cambridge University Press, 1997.

MCCHESNEY, R. W. Rich media, poor democracy: communication politics in dubious times. Urbana: University of Illinois Press, 1997. 
MCCOMBS, M. e SHAW, D. The agenda-setting function of mass media. Public Opinion Quarterly, vol. 36, n 2. New York, p. 176-87, 1972.

MERTON, R. K. e LAZARSFELD, P. F. Comunicação de massa, gosto popular e a organização da ação social. In: LIMA, L. C. (org.). Teoria da cultura de massa. $2^{\mathrm{a}}$ ed. Rio de Janeiro: Paz e Terra, 1978 [1948].

MICHELS, R. Sociologia dos partidos políticos. Brasília: Editora UnB, 1982 [1914].

MIGUEL, L. F. O jornalismo como sistema perito. Tempo Social, vol. 11, nº 1. São Paulo, p. 197208, 1999a.

. Mídia e manipulação política no Brasil: a Rede Globo e as eleições presidenciais de 1989 a 1998. Comunicação \& política, nova série, vol. VI, n² 2-3. Rio de Janeiro, p. 119-38, 1999b.

2002.

Os meios de comunicação e a prática política. Lua Nova, n 55-6. São Paulo, p. 155-84,

A eleição visível: a Rede Globo descobre a política em 2002. Dados, vol. 46. Rio de Janeiro, 2003, no prelo.

NORRIS, P. A virtuous circle: political communications in postindustrial societies. Cambridge: Cambridge University Press, 2000.

OFFE, C. Dominação de classe e sistema político: sobre a seletividade das instituições políticas. In: Problemas estruturais do Estado capitalista. Rio de Janeiro: Tempo Brasileiro, 1984 [1972].

REIS, F. W. Governabilidade, instituições e partidos. In: Mercado e utopia: teoria política e sociedade brasileira. São Paulo: Edusp, 2000.

SARTORI, G. A teoria da democracia revisitada, 2 v., São Paulo: Ática, 1994 [1987].

. Videopotere. In: Elementi di teoria politica. Bologna: II Mulino, 1987.

Videopolitica. Rivista Italiana di Scienza Politica, vol. XIX, nº 2. Roma, p. 185-98, 1989.

Homo videns: la sociedad teledirigida. Buenos Aires: Taurus, 1998 [1997].

SOARES, G. A. D. Sociedade e política no Brasil. São Paulo: Difel, 1973. 
SOUZA, M. C. C. Estado e partidos políticos no Brasil. São Paulo: Alfa-Ômega, 1976.

TUCHMAN, G. Objectivity as strategic ritual: an examination of newsmen's notions of objectivity. American Journal of Sociology, vol. 77, $\mathrm{n}^{\circ}$ 4. Chicago, p. 660-79, 1972.

Making news by doing work: routinizing the unexpected. American Journal of Sociology, vol. $79, n^{\circ} 1$. Chicago, p. 110-31, 1973.

WATTENBERG, M. P. The decline of American political parties, 1952-1996. Cambridge (MA): Harvard University Press, 1998. 